\title{
Reference situations for biodiversity in life cycle assessments: conceptual bridging between LCA and conservation biology
}

\author{
Emke Vrasdonk $^{1,2}$ (D) Ulrika Palme ${ }^{1,2} \cdot$ Tommy Lennartsson $^{3}$
}

Received: 29 June 2018 / Accepted: 10 February 2019 / Published online: 27 February 2019

(C) The Author(s) 2019

\begin{abstract}
Purpose In life cycle assessment (LCA) literature addressing land use impacts on biodiversity, several potential reference situations are proposed. However, the lack of guidance on how to apply the proposed reference situations fosters confusion within the topic and raises questions about implications of different reference conceptions. The purpose of this article is to contribute to an improved methodology for assessing biodiversity impacts in LCA through developing the use of reference situations in life cycle impact assessment (LCIA) models of land use.

Methods We analyze how reference situations are currently used when assessing the impacts from land use on biodiversity, as well as how such are defined and used outside LCA, specifically in biodiversity conservation. Based on this review, we provide recommendations to the LCIA research community on how to modify its use of reference situations to enable more relevant assessments of impacts on biodiversity.

Results and discussion It is shown how, in the LCA framework, the use of so-called baseline references dominates, and what shortcomings this implies, including unclear definitions of what "naturalness" and "pristine nature" represent, as well as the lack of reliable data. By contrast, biodiversity conservation, typically aiming at ensuring a favorable conservation status for biodiversity, normally uses limit and target references. These reference situations have the advantage of reflecting, often at an aggregated level, society's preferences, and values related to biodiversity. Because of this, they also include biodiversity that is dependent on a certain level of management, as in, e.g., semi-natural pastures. This is an important aspect as much of the biodiversity highly valued today belong to this category.

Conclusions We recommend that reference situations for biodiversity in LCIA models should be developed based on biodiversity targets aligned with society's conservation frameworks. Only measurements of deviation away from or closer to a desired reference situation make it possible for decision makers to distinguish the varying biodiversity-related costs and benefits that are associated with different production systems.
\end{abstract}

Keywords Biodiversity $\cdot$ Biodiversity conservation $\cdot$ Land use $\cdot$ LCIA $\cdot$ Reference situation

Responsible editor: Miguel Brandão

Emke Vrasdonk

emke.vrasdonk@chalmers.se

1 Environmental Systems Analysis, Department of Technology Management and Economics, Chalmers University of Technology, 41296 Gothenburg, Sweden

2 Gothenburg Global Biodiversity Centre, 405 30 Gothenburg, Sweden

3 Swedish Biodiversity Centre, Swedish University of Agricultural Sciences, 75007 Uppsala, Sweden

\section{Introduction}

Biodiversity - crucial for ecosystems' health and their products and services - is being lost at an alarming rate. Consequently, the preservation and sustainable use of biodiversity are prioritized societal goals that are subject to global conventions (FAO 2009; UN CBD 2010; Ramsar Convention Secretariat 2013) and operationalized through conservation frameworks at global, regional, and national levels (IUCN 2016). A key task in conservation efforts is to assess impacts on biodiversity of human interventions, from direct use of ecosystems and resources to unintentional effects of products and services. Impact on biodiversity has also been recognized as an important aspect in life cycle assessment (LCA), which 
is a widely used method for assessing environmental impact. As will be shown in the following paragraphs, several LCA models have been proposed for assessing biodiversity loss. So far, application of models and knowledge from biodiversity conservation in LCA has been very limited, but there appears to be a growing awareness of the importance of learning from ecology and conservation (Curran et al. 2016).

Within the framework of the UNEP-SETAC International Life Cycle Initiative, a partnership formed by the United Nations Environment Programme (UNEP) and the Society for Environmental Toxicology and Chemistry (SETAC), an international panel of LCA experts, has completed the Land Use Life Cycle Impact Assessment (LULCIA) project (Koellner et al. 2013; Frischknecht et al. 2016a). Following on some other pioneers, the LULCIA project established preliminary models for incorporating land use impacts in LCA. As a starting point for including land use impacts in LCA, two types of land use interventions are usually considered in life cycle inventories and impact assessments: land transformation (also called land use change, LUC) and land occupation (land use, LU) (Lindeijer 2000; Milà i Canals et al. 2007 among others). During land transformation, a piece of land (natural or already in use) is transformed to another land use type. The process of transformation itself is usually very short in relation to the time of land occupation; thus, the time it takes to transform the area is often set to zero. Occupation of land is defined as the use of the land as envisioned, while reversal or regrowth of the (semi-) natural status of the land is postponed (Weidema and Lindeijer 2001; Koellner and Geyer 2013). If land after transformation is not occupied and thus not maintained, a more natural state will slowly develop due to natural processes (Milà i Canals et al. 2007). It could be assumed that after a certain regeneration time, the land quality of the initial situation would be fully re-established. Both earlier natural states and earlier land-use-generated states may, however, be difficult to reach in land that has been heavily changed. It is more likely to reach a steady state of which the quality deviates from the earlier one, or the regeneration time could be longer than the modeling horizon of the LCIA. In both of these cases, the changes in quality may be regarded as permanent impacts (Weidema and Lindeijer 2001; Koellner and Geyer 2013; Koellner et al. 2013). The theoretical framework for assessing impacts of land use interventions on land quality as a function of time is shown in Fig. 1. The figure should be interpreted as follows: At time $t 1$, land is transformed to another land use type. This change results in a drop of the quality of the land from $Q r e f$ to $Q L U 1$. At time $t 2$, the area is transformed again for another purpose and the quality drops from $Q L U 1$ to $Q L U 2$. At $t 4$, the land lies fallow since it is not in use anymore and recovers. After the recovery time $t L U 2$, reg, there will be established a new steady state at $t 5$. This new steady state Qref2 is not necessarily the same as the original quality and could be either of lower or higher quality than before. In this example, the quality Qref2 of the land does not reach the initial reference quality (Lindeijer et al. 2002; Koellner et al. 2013).

A crucial variable in the established framework is the reference situation (Qref and Qref2 in Fig. 1) (Koellner et al. 2013; Michelsen and Lindner 2015; Teixeira et al. 2016). We use the term reference situation to represent a situation against which land use and land transformation interventions can be evaluated through some measure of change in quality, in this case biodiversity. Thus, the biodiversity impacts of an intervention can be quantified as the difference between the quality of the land as a result of the intended use and the reference situation. However, this reference situation could be a point in the past, present, or future (De Baan et al. 2013a), and its choice could imply different results and conclusions (Michelsen et al. 2014; De Baan et al. 2015; Nordborg et al. 2017), complicating comparison between characterization factors derived by different LCIA models (Nordborg et al. 2017; Vidal Legaz et al. 2017).

In consequential LCA, it is generally accepted that the focus on marginal changes makes the most probable alternative land use the appropriate reference (Milà I Canals et al. 2007; Cao et al. 2017; Koponen et al. 2018). In literature addressing biodiversity assessments in attributional LCAs, however, the most appropriate reference situation has been debated and many different reference situations have been proposed. Most of them are reference situations that reflect a time period or situation free from human pressures. Examples are a preanthropogenic disturbance state (Blonk et al. 1997; de Schryver et al. 2010; Scholes and Biggs 2005, among others), (semi-) natural land cover (Koellner et al. 2013; Brentrup et al. 2002; Wagendorp et al. 2006; De Baan et al. 2013a, b), and Potential Natural Vegetation (PNV) (Chiarucci et al. 2010; Souza et al. 2013; Koellner et al. 2013).

Despite the variety of reference situations proposed, only few authors give guidance on how to apply and measure the proposed reference situations to enable the calculation of characterization factors. This leads to poor approximations of reference situations, and the distinction between different reference situations is not clear (Vrasdonk et al. 2016). Reference situations as PNV, pre-anthropogenic disturbance state, and relaxation potential - whose rationale set out from a "human-free" situation - are all approximated with data on semi-natural ${ }^{1}$ land cover in the region.

The purpose of this article is to contribute to an improved methodology for assessing biodiversity impacts in attributional LCA through identification and comparison of different

\footnotetext{
${ }^{1}$ Semi-natural is generally defined as vegetation not planted by humans but influenced by human actions. These may result from grazing, possibly overgrazing, or else from practices such as selective logging in a natural forest whereby the floristic composition has been changed (Di Gregorio and Jansen 2000), but how much semi-natural departs from natural varies between different contexts.
} 
Fig. 1 Evolution of land quality with land use interventions (adapted from Koellner et al., 2013)

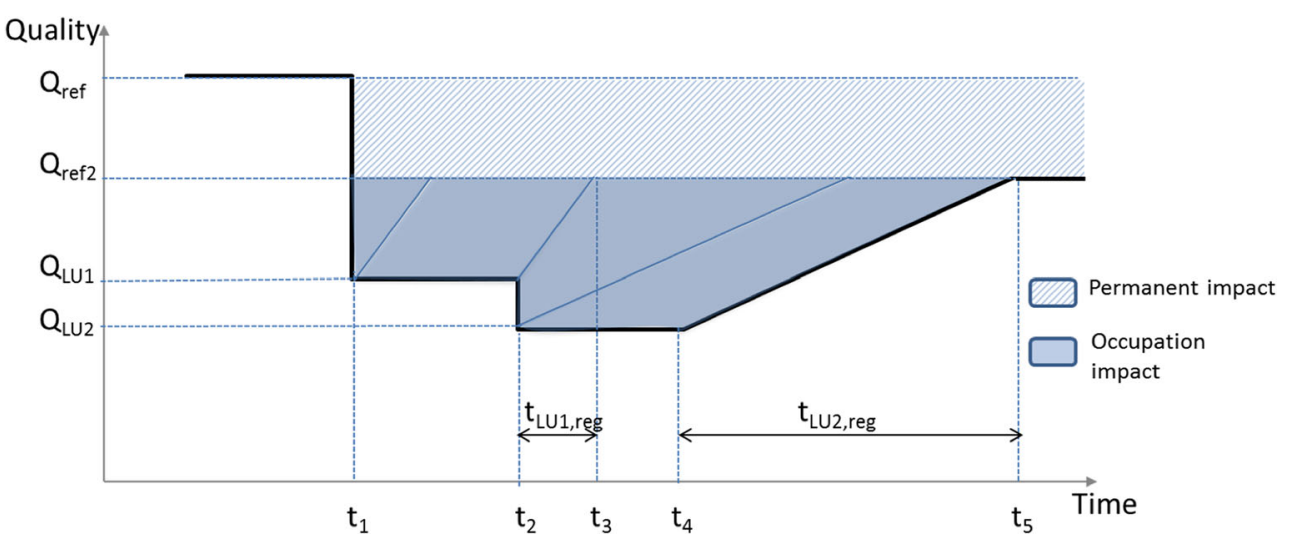

standards by which reference situations are currently applied in LCIA models and biodiversity conservation. The fact that the term reference situation has a variety of interpretations and definitions allows for a wide range of impact quantifications, but that same diversity hinders the conceptual consistency needed in LCIA models. To evaluate the conceptual understanding of reference situations and their implications, this paper is organized in the following manner: (1) identification of strengths and weaknesses of the reference situations currently used in LCIA models addressing impacts on biodiversity, (2) evaluation of the relationships between the use of reference situations in such LCAs and the aims of biodiversity conservation, and (3) an analysis of how LCA can be developed to better fit biodiversity conservation practices.

\section{Terminology of reference situations}

Conservation biologists, restoration practitioners, and LCIA modelers all utilize some kind of reference concepts in their work. From a conservation policy and management perspective, every ecosystem or biodiversity indicator must be linked to a reference level that represents a desired state (Pitcher 2001; Rice 2003). Some fairly well-established reference levels in biodiversity conservation practice include for example target population sizes for recovery of endangered species (Gerber and Hatch 2002), the harvest rate corresponding to maximum sustainable yield in fishery (Walters and Martell 2004), and the critical level of nutrient input beyond which a clear freshwater lake becomes turbid (Schindler 1974). The terminology for reference concepts may, however, not be exactly the same across different disciplines and practitioners. For ease of communication, we here clarify the terminology used in this paper to distinguish between several kinds of reference situations.

The term reference situation itself is a broad concept, describing any starting point against which we can quantitatively compare another situation (Frischknecht et al., 2016b). The term baseline reference situation describes a more specific reference situation, representing land in its original, unmanaged, state. In principle, a baseline reference is derived from time periods or locations in the absence of human intervention. The term can thus be used for an ecosystem state prior to (substantial) human impact, during some time period in the past or the current situation in areas protected from human impacts. Because of long-term climate change or other changes, some situations of a distant past would not have prevailed today in spite of absence of human interventions. Here, it is more feasible to identify a hypothetical situation that would have occurred nowadays without interventions in the past. We refer to this alternative baseline scenario as a natural counterfactual.

One commonly used reference situation is the re-naturalization reference or natural regeneration, which describes a future hypothetical state after all human interventions had stopped. It differs from the natural counterfactual because the re-naturalized state is partly a result of human activity in the past. Reference situations can also be established as limit references that, if exceeded, indicate that the system or object will be subject to serious or irreversible harm.

In conservation policy and practice, target reference situations are used that signal a state at which to aim, given ecological needs and socioeconomic and political possibilities (Ices 2002; Jennings and Dulvy 2005; Frischknecht et al., 2016a; Verones et al. 2017). Target references may be baselines, re-naturalized states, limit references, or something else.

\section{Evaluation of reference situations used in LCIA of land use}

In the following sections, we analyze how reference situations are used in current life cycle impact assessment models addressing biodiversity. First, it is discussed how reference situations fit in the established LCA framework. In the second part, the practical challenges associated with applying these reference situations are discussed. 


\subsection{Reference situations in the LCA framework, a theoretical background}

The first studies discussing the application of a reference situation for biodiversity in LCA of products state that the reference for land use should describe the situation in the absence of the studied product system (Weidema and Lindeijer 2001; Milà i Canals et al. 2006, 2007; Michelsen 2008), i.e., a baseline reference situation that describes a human-free situation against which the impacts of the studied land use are assessed. The rationale behind this lies in the fundamental goal of LCA, which is the compilation and evaluation of the inputs, outputs, and the associated potential environmental impacts of a product system (covering both goods and services) across the whole life cycle. Its results are used to aid in decision-making, choice of environmental performance indicators, and support market claims (ISO 2006), often aiming at improvement in the system (Ekvall and Tillman 1997; Baumann and Tillman 2004). In order to achieve these fundamental goals, LCA divides the world into a technosphere and an ecosphere in which changes to the ecosphere (as a result of activities in the technosphere) can be considered unintentional "man-made" consequences (Hauschild et al. 2017). However, the location of the boundary of these two spheres is quite abstract and therefore often debated with regard to agricultural systems for example (Hauschild et al. 2017). Yet, as this is the way LCA is constructed, several authors point out that including parts of the technosphere in the reference situation should preferably be avoided in attributional LCA (Soimakallio et al. 2015; Brander 2016). Herewith, they exclude reference situations that are not completely natural, like current land use mix as proposed by Koellner and Scholz (2008).

The reasoning above explains the preference for baseline or other natural reference situations in current LCA practices, i.e., a historical "natural" situation, a natural counterfactual situation, or a re-naturalization situation.

When using historical baseline references, usually a point in time is selected to compare against current conditions to. Without a sufficiently distant past, however, these references may fail to fully inform about past human impacts. Choosing a timeframe is therefore not straightforward; how far back in time do we have to go? Obviously, going back to times in which the wooly mammoth was still around, some 10,000 years ago, would not appear be relevant for current assessments of current land use impacts, but identifying a closer "pristine nature" time period might be challenging, as human land use history varies strongly from region to region (e.g., Hilding Rydevik et al. 2018). To be able to compare impacts of land use in different landscapes, time frame and level of degradation of the reference should be equal, if not to be compromised (Nielsen et al. 2007).

The change of ecosystems without human interventions is normally neglected when natural baselines are used. In principle, the effect of land interventions on biodiversity can only be explained if the expected trends of biodiversity in the absence of these interventions are known, thus if a natural counterfactual reference situation is used. In landscape-level ecological research, these types of expected patterns on landscape scale have been used and termed neutral landscape models (NLM) in the tradition of neutral or null models in ecology (Ricotta et al. 2002). Potential natural vegetation (PNV), which has been used in LCIA models, is such a neutral model, developed to express the biotic potential of a region with regard to all site factors relevant for vegetation development (Ricotta et al. 2002), thus the hypothetical natural status of vegetation that could be outlined for the present time or for a certain earlier period, imagining that the area would never have been subjected to human interventions (Tüxen 1956). PNV is a much-debated concept with many different interpretations (Curran et al. 2016). It has been interpreted both as a future hypothetical state after all human interventions had stopped (a re-naturalization reference), and as a preanthropogenic disturbance state, i.e., some kind of "climax" natural state (a historical reference) (Chiarucci et al. 2010). In the LCA literature, the latest recommendations point out that the appropriate definition should be "hypothetical biotic potential" of a region based on patterns in existing remnants of maximally undisturbed vegetation in which case existing remnant vegetation must act as a source for colonizing species following abandonment and succession (Curran et al. 2016). This makes the PNV a re-naturalization reference, rather than a natural counterfactual reference situation.

Re-naturalization has been identified as the most suitable reference situation for use in attributional LCA by several authors (Milà i Canals et al. 2007; Soimakallio et al. 2015; Curran et al. 2016; Koponen et al. 2018), as land occupation postpones natural regeneration of the land and the fact that the resulting final ecosystem could be of a different "quality" than the original. These impacts are permanent and need to be accounted for (Weidema and Lindeijer 2001) (Fig. 1). However, by solely using a re-naturalization reference situation, we would only catch how much impact additional land use would cause. Earlier land use impacts would be impossible to calculate without comparison to the situation as it was before the land use started (historical) or the counterfactual reference situation. Mathematically, in an assessment using only a renaturalization reference situation to quantify biodiversity impacts, further degradation of the land due to changed land use management might actually result in a lower estimated impact if the degradation in question limits the capability of the land to regenerate (Soimakallio et al. 2015). In the same way, use of land with a high potential to regenerate would cause a higher impact than the same usage of land with a lower regeneration potential (although in some cases, this effect might be compensated for by a higher production ratio). To prevent this potential "gap" in impact results, it would be of importance that an 
assessment that quantifies land occupation impacts related to a re-naturalization reference also includes the quantification of permanent impacts (related to a baseline reference as natural situation or natural counterfactual situation). In other words, complying to the UNEP-SETAC framework for land use impacts in LCA would mean that two reference situations would have to be established: both a natural situation or natural counterfactual situation as well as the re-naturalization reference. The use of a double reference situation to calculate land use impacts is, however, rarely seen in impact assessment models for biodiversity (or any other land use impacts), as it is far from practical considering the difficulties and uncertainties involved in applying reference situations, as described in the section below. We thus discourage the distinction between occupational and permanent biodiversity impacts unless a double reference situation can be established. As a re-naturalization reference situation by principle only catches occupational impacts and neglects permanent impacts, a re-naturalization reference is unsuitable in assessments using a single reference situation. There are, however, examples where the natural or baseline reference situation is implicitly present. For example, in the model by Curran et al. (2016) based on conservation status of species (the IUCN red list of threatened species), a baseline reference situation is applied due to the use of contemporary threat/rarity data. In this case, the application of a renaturalization reference situation allows for assessing the potential permanent impacts expressed as the extinction risk of species.

A fourth group of reference situations used in LCA, although considerably less often so than the baseline references discussed so far, are the target reference situations. Several authors point to the reference situation as a possible benchmark of a desired direction for ecosystem management, improvement, or restoration (Curran et al. 2016; Teixeira et al. 2016; Verones et al. 2017). Some authors argue that regardless of which reference system is chosen, the reference situation reflects per definition a desired situation (Cao et al. 2017), others, like us, regard a target situation as one of multiple types of reference situations, besides, e.g., a (hypothetical) situation representing conditions in the absence of human intervention or a current situation (Frischknecht et al. 2016b). This view is motivated by the fact that a specific type of natural reference situation (i.e., a human free reference or renaturalization reference) will not represent a desired situation in all cases. For example, the re-naturalization reference does not address active land restoration or other forms of human land management in habitats depending on this (Souza et al. 2015). Lindner et al. (2014) proposed a biodiversity impact assessment model applying the desired (target) state of biodiversity as defined in national strategy documents as the reference situation. The model has been applied by, e.g., Lindqvist et al. (2015), and further developed by Winter et al. (2018). In the case of Lindqvist et al. (2015), it should be noted that the advocated desired state ended up being interpreted as a maximum natural value, which illustrates the earlier stated fact that target references can take different shapes. We elaborate on the differences between baseline reference situations and target reference situations in Sect. 4.

\subsection{Challenges in applying baseline reference situations}

Going beyond theory, successfully applying a reference situation into LCA practice, means that the reference situation has to be translated into a set of functional reference conditions, a set of attribute values or quantifiable characteristics of the reference situation (Miller et al. 2012). These types of attributes will depend on the indicators chosen to assess biodiversity and can be physical, chemical, or biological parameters of organisms, ecosystem functions, or structures, and could be represented by single values or a distribution (Miller et al. 2012).

In LCIA, there is a wide variety of indicators applied, see, e.g., Curran et al. (2011), Michelsen and Lindner (2015), Souza et al. (2015), and Winter et al. (2017) for reviews. In brief, the most frequently used biodiversity indicator in LCIA models is $\alpha$-diversity (number of species in an area) calculated by use of a species-area relationship (SAR) model. Lately, the diversification of indicators for capturing biodiversity has increased, as has the tendency to recommend multiple indicators. The list of suggested indicators in LCIA now includes ecological scarcity (ES), ecological vulnerability (EV) and structural indicators (Michelsen 2008), functional diversity (Souza et al. 2013), and indicators based on expert knowledge (e.g., Jeanneret et al. 2014; Lindner et al. 2014; Lindqvist et al. 2015). Indicators capturing the genetic level of biodiversity remain few (Winter et al. 2017).

The reference situation is decisive for what indicators can be applied, as data must necessarily be available for the reference situation. Irrespective of LCIA model and indicator selected, finding reliable data for baseline situations is often complicated, and more so when that baseline is not integrated in the indicators used but rather relying on the assessment of actual sites representing the baseline reference situation. Such sites are difficult to find in many parts of the world, as few or no areas remain that have not been under human influence of some kind. Therefore, the sites chosen are often those considered to be "the best of what's left." As a result, if we aim for natural situations, we often end up with a reference that departs from the natural state by some unknown amount. The struggle to find a baseline reference situation that is measurable shows clearly in current LCA studies, where reference situations as potential natural vegetation, pre-anthropogenic disturbance state, and relaxation potential are all approximated with data of semi-natural land use in the region (Weidema and Lindeijer 2001; De Schryver et al. 2010; Souza et al. 2013). Due to the varying departure of semi-natural from the natural, 
semi-natural conditions cannot deliberately be used as a proxy for the natural (FAO 2002).

In many cases where we desire naturalness, we have to accept that in some places, the baseline has shifted and that we have lost the chance to conserve (or even identify the loss of) the most vulnerable habitat or species. There is then no other option than to estimate the reference situation by quantifying the biological condition at a set of sites that are either minimally or least disturbed by human activity (Stoddard et al. 2006). However, the characterization of even sub-optimal sites as reference situations can still provide a valuable guide. This kind of logic introduces the notion of "best-available condition" or "least-disturbed condition" as the most appropriate, and indeed only, baseline reference for many areas of the world (Gardner 2010; Stoddard et al. 2006).

Available monitoring data provide a starting point for historical baseline references. However, most biodiversity monitoring schemes were initiated late in the twentieth century, whereas land use, just like most of the anthropogenic pressures that are currently impacting biodiversity, has been operating for over centuries or even millennia (Mihoub et al. 2017). This mismatch between the long history of land use and the limited temporal frame of the biodiversity monitoring schemes, together with geographical and taxonomic biases of the data, limits the assessment of full impacts on biodiversity (Mihoub et al. 2017). Other problems arise when historical data is not linked to a bigger monitoring plan, as time frame and level of degradation of the reference should be equal to prevent misleading results, i.e., due to climate variation (Nielsen et al. 2007; Borja et al. 2012). In conclusion, due to the absence of historical records in many parts of the world, a baseline reference situation is often inapplicable.

\section{Reference situations in relation to biodiversity conservation}

Since LCA-models are powerful decision aids, they can not only be helpful but also harmful if a model's foundational assumptions and/or its results are misinterpreted or point decision makers in a sub-optimal direction. Alternatively, the results will not be paid attention to if they are considered by practitioners or policy makers not to match existing policies or established targets and strategies. Therefore, in order to be societally useful, life cycle impact assessment (LCIA) models aiming to include biodiversity impacts need to address such biodiversity impacts that are applicable for current conservation strategies and policies (Teixeira et al. 2016), and in a way that produce results that can be translated into indicators used in conservation, such as area and or quality of habitats, and conservation status of species.

Several of the reference situations commonly used in LCA, especially those aiming at naturalness (baseline reference situations as historical state, climax state, natural state, renaturalization potential), differ considerably from conservation targets. For example, the global Convention on Biodiversity (CBD) which is based on the vision "Living in Harmony with Nature" does not aim predominantly at naturalness but emphasizes the sustainable coexistence of humans and biodiversity by stating that "By 2050, biodiversity is valued, conserved, restored and wisely used, maintaining ecosystem services, sustaining a healthy planet and delivering benefits essential for all people" (UN CBD 2010, p. 8). The European Species and Habitats Directive (Council Directive 92/43 EEC) aims at maintaining or restoring Europeanprotected habitats and species listed in the Annexes at a favorable conservation status. Many of the listed habitats are anthropogenic and their species dependent on continued landuse (The Council of the European Communities 2013). Biodiversity conservation, typically aiming at ensuring favorable conservation status for biodiversity, usually works with target and limit reference situations (Epstein et al. 2016). Although target and limit reference situations are fairly well established in biodiversity conservation assessments, the LCA community has rarely applied them in impact assessment models for biodiversity. The methodology recommended in Chaudhary et al. (2015), which is also the one recommended in the UNEP-SETAC Global guidance for LCIA indicators (Frischknecht et al. 2016b), implicitly includes a target, as it implies the calculation of vulnerability scores for threatened species. Similarly, methods applying indicators of ecosystem scarcity and/or vulnerability (e.g., Weidema and Lindeijer 2001; Michelsen 2008) also implicitly include a target. This could be developed further to align with explicit conservation targets, including not only species but also habitats and their management. There are, notably, other LCIA models wherein limit and/or target reference levels have already been successfully applied. For example, in the calculation of acidification and eutrophication potentials, critical loads serve as limit reference, while toxicity potentials have been calculated based on the ratio of Predicted (No) Effect Concentration, PEC/ PNEC (Huijbregts 1999).

The integration of biodiversity in LCA may be viewed as a wicked problem (Churchman 1967), as biodiversity is composed of a myriad of components in dynamic relationships, which contrasts the need for simplification inherent to LCA. Due to the complex nature of biodiversity, it can be measured in different ways and an all-inclusive single metric for biodiversity is non-existent (Teillard et al. 2016). A model builder aiming at including biodiversity impacts in LCA thus has to look at the ecological and societal context of biodiversity in the specific case of modeling. Doing so, it will be evident that no single biodiversity "optimum" exists that can be applied over all cases, and by trying to establish one, trade-offs related to different types of biodiversity, e.g., species groups, and value perceptions of those biodiversity effects, are inevitable. This 
implies, firstly, that every model is valid only for the particular type of biodiversity (subset of species, habitats, etc.) that we study and, secondly, that models will measure environmental quality according to an anthropocentric value judgment, rather than biological integrity. Hence, also the choice for a baseline reference situation such as pristine nature is an anthropocentric judgment. The baseline reference situation may be chosen for some ecosystems and habitats in which biodiversity benefits from naturalness, for example old-growth forest, high alpine habitats, and many types of wetland. In other ecosystems and habitats in the cultural landscape, such as pastures and hay meadows, biodiversity rely on continued land-use, often of traditional types and non-natural target reference situations need to be used. In other words, in our trials to measure biodiversity impacts "objectively" with the help of a baseline reference situation, we fail. The result is an anthropocentric measurement of biodiversity which does not reflect "true" impact on biodiversity, neither a desired direction for biodiversity conservation. Instead, it is necessary to define reference situations that reflect favorable conservation status and sustainable use of each specific type of biodiversity, some of which may be characterized by naturalness, others by human land-use. In this way, the reference situation is used to facilitate a distance to target measure, which can be justified if we do not only aim to conserve diversity of wild species but also of their cultivated, farmed, and domesticated relatives as well as other socioeconomically and culturally valuable species. This gives room to man-made environment in the reference, i.e., assessing impacts against historical ecosystem processes and cultural landscapes in a manner that accounts for long-term human occupancy rather than supposedly pristine landscapes. Only measurements of deviation away from a desired target reference situation enable decision makers to distinguish the varying costs and benefits to biodiversity that are associated with alternative production systems.

\section{Biodiversity conservation, preserving what is valued}

Developing a model to quantify biodiversity impacts is not a problem to be solved in isolation. Caution is needed not only regarding what to assess but also regarding what to preserve. Similar to all societal objectives for environmental quality, the decision to preserve biodiversity at certain conservation status is a value judgment. Value systems vary between stakeholders depending on one's perspective on biodiversity. Biodiversity can be viewed from at least three vantage points: biophysical science, economics, and social aspects (Sharman and Mlambo 2012). Divergent perspectives imply a conflict between the preservation and utilization aspects of biodiversity conservation, as reflected in the often opposing perceptions of, e.g., farmers and conservation authorities, or hunters and tourists (Gusset et al. 2008; Sharman and Mlambo 2012). Also within the utilization dimension of conservation, the choice of reference situation for assessing sustainable use differs depending on what natural product an actor utilizes.

The different perspectives and priorities regarding biodiversity are brought together in national policies for conservation and land-use. National policies align, more or less closely, with international agreements such as global conventions (e.g., CBD and CITES) (UNEP 2016), and regional multilateral laws or conventions (e.g., the European Union common laws, the Bern Convention, Convention on the Protection of the Alps, and the African Union Convention on the conservation of nature and natural resources) (Medaglia et al. 2014). Most of the world's conservation efforts serve the double purposes of preserving the Earth's diversity of organisms in functional ecosystems and using biodiversity sustainably, which is emphasized in, for example, the global Convention on Biodiversity (CBD). The three objectives of the Convention - conservation of biodiversity, sustainable use of its components, and the fair and equitable sharing of the benefits arising out of the use of genetic resourcesexplicitly recognize humans as an integral component of these systems (Willis et al. 2007). This is in contrast with the LCA approach which tries to separate the technosphere from the ecosphere and in which disturbances, which drive changes in ecological variability, are usually characterized as either natural or human. It is, however, clear from examinations in the past that humans have been an integral part of many ecosystems for at least 100,000 years (Willis et al. 2004). Many important habitats for biodiversity and wildlife have been created and maintained by millennia of extensive, low-intensity land use such as mowing, grazing, or burning. These practices make many cultural landscapes of utmost importance for biodiversity today (Norderhaug 2007; Oppermann and Paracchini 2012).

The preservation aspect of conservation in itself is somewhat less value-based than the discussion around the preservation vs. utilization aspects, since most of the work with preserving endangered biodiversity aims at "favourable conservation status." Conservation frequently focuses on endangered biodiversity, not because it is considered more valuable, but because it requires special attention compared to non-threatened biodiversity. This can be considered a limit reference situation, because favorable conservation status requires certain levels of critical environmental and biological parameters (IUCN 2012). Even if conservation status can thus be rather objectively assessed, the allocation of resources to conservation activities in practice is always subject to value judgements. Some stakeholders, for example, focus on a few conspicuous symbolic species, e.g., large carnivores, whereas others focus on functional ecosystems for whole species assemblages. Numerous other priorities for action include costs, logistics, and chances of success (Marsh et al. 2007; Joseph et al. 2009).

Although preservation conservation mostly applies a limit approach, there are examples where a baseline reference situation is chosen. When choosing between conservation relating 
to a baseline reference situation, and conservation based on a limit approach, e.g., favorable conservation status, the significance of value judgements in conservation is, again, striking. The application of a baseline reference situation provides favorable conservation status only for species in those habitats that have the highest ecological functionality in the absence of human impact, for example, some habitats in old-growth forest, high alpine and mire ecosystems, and most aquatic ecosystems (Hannah et al. 1994; Kapos and Lysenko 2000; Groombridge and Jenkins 2002; Reif and Walentowski 2008; Keddy 2010). In cultural landscapes, semi-natural ecosystems have been formed by a long history of land-use, and biodiversity is instead depending on continued traditional land-use (Ihse 2007; Emanuelsson 2010; Lennartsson et al. 2018). Moreover, several studies have indicated that many allegedly natural ecosystems may actually be influenced by land-use to a degree that questions the relevance of using a baseline reference in conservation (Kopf et al. 2015; Hilding Rydevik et al. 2018). It should be noted that some conservationists may aim at either minimizing human impact or restoring traditional land-use for other reasons than the effects on conservation status for species and habitats. In human-made ecosystems and human-influenced landscapes, traditional land-use maintains a biocultural heritage and biocultural diversity, as well as traditional ecological knowledge (Ihse 2007; Norderhaug 2007; Iuga et al. 2018; Lennartsson et al. 2018). This so-called naturalness direction was dominating in the early days of conservation, founded in contemporary movements and societal norms (e.g., the greening of nationalism or the "Green political thought"; nationalism and ecologism, Hamilton 2002). Today, advocates for naturalness are found, for example, in the rewilding movement, aiming at re-introducing large herbivores and carnivores and excluding humans from certain landscapes (Soulé and Noss 1998; Pereira and Navarro 2015; Nogués-Bravo et al. 2016).

\section{Implementation of target-based reference situations}

The implementation of a target reference situation in LCIA models would demand, first, a reconsideration of the land use and land transformation impact framework as proposed by the LULCIA project group from the UNEP-SETAC as the framework in his current form might not support distance to target measures for biodiversity. Second, existing targets for biodiversity within global, regional, and national conservation frameworks need to be assessed in order to find verifiable and measurable targets that can be used as reference situations in quantitative life cycle impact assessment models.

Within the overarching goal to preserve biodiversity at favorable conservation status and to use it sustainably, several quantitative goals exist in conservation, many of which could serve as target reference situations in LCIA modeling. These targets may be defined at a variety of levels of biological organization (e.g., populations, species, and communities) and spatial scales of the interactions between organisms and their environment, such as ecosystems, landscapes, and biomes (e.g., Putman and Wratten 1984, ch. 2). Indicators for conservation status are developed to measure either populations, species or communities directly, or components of the species' environment, both biotic and abiotic features (Pressey et al. 2003), which fit well with indicators applied in LCIA models.

At the species level, conservation status is objectively evaluated using the international IUCN framework, which is based on data of population size, trends, and distribution in relation to limit reference values for different degrees of threat to species (IUCN 2012). This framework can be used anywhere, using best available knowledge. For example, according to the Swedish implementation of the IUCN criteria, a species is considered threatened if it shows a population decline of $>15 \%$ during 10 years or three generations, or if it has a distribution area less than $40,000 \mathrm{~km}^{2}$ in combination with pronounced fragmentation, ongoing decline, or extreme fluctuations of population size (Swedish Species Information Centre 2015).

At the habitat level, status of habitats that are important for biodiversity is assessed, for example, within the European Species-Habitats directive, based on parameters as former and current areas, and the habitats' contents of key elements and processes (European Commission 2013; Evans 2010). Important habitats include both natural ones (little human impact) and habitats formed by pre-industrial (traditional) land-use, such as semi-natural pastures and hay-meadows (Lennartsson and Helldin 2007). Typically, a habitat is considered to have favorable conservation status if its total area reaches a certain proportion (often 20\%, Angelstam and Andersson 2001) of the estimated maximum area. Furthermore, certain structures and functions are required for single habitat patches to have favorable conservation status. Examples are dead wood (of certain tree species, decomposition stages, levels of sun exposure, etc.), old-growth trees, hollow trees, grazing-generated ground vegetation, and occurrence of typical habitat-specific species (Evans and Arvela 2011). The frameworks for assessing habitat status can be seen as pragmatic simplifications of habitat suitability models (Borja et al. 2012), adapted to what information is available and in order to be practically useful (Margules and Pressey 2000). Within the Convention on Biodiversity, conservation status of biodiversity, as well as of strategies and action plans, is regularly reported by every member country based on a number of criteria (for the fourth national reports, see https://www.cbd. $\mathrm{int} / \mathrm{reports} / \mathrm{nr} 4 /$ ). These reports reflect quantitative or qualitative distances between national targets and the current status of biodiversity, for example in different biomes. Changes of status can be expressed, for example, as number and magnitude of threats. 
In summary, within the existing conservation frameworks, the status of biodiversity is assessed in relation to defined targets using a variety of methods that are designed in order to be practically workable and adapted to the available knowledge. Some estimates are based on quantitative levels of, e.g., population sizes, areas of species distribution or habitat, or amount of key elements within biotopes. In many cases, the direction of trends of those parameters is used rather than the absolute values. These direct indicators of conservation status are complemented with several indirect indicators, such as numbers of different threats and numbers and area of protected biotopes. Some estimates should be possible to use directly in LCA, and others require adapted models, but all aim at assessing the distance between a politically set target and the current situation.

\section{Conclusions}

In biodiversity conservation, the choice of reference situation is founded in a combination of biological needs, current policy, societal norms, and practicalities, and may hence be anywhere between pristine nature and completely human-made. In LCA, in contrast, the predominance of baseline reference situations appears to be an effect of the structure of the LCA framework. The approach to measure impacts of land use relative to a baseline reference situation, or "the natural," is embedded in the current UNEP-SETAC framework for land use life cycle impact assessment. However, this approach has shown limited compliance with current conservation strategies. Given the role of LCA in decision-making, it is of importance that impact assessment models address biodiversity impacts in a way that make the assessment compatible with current conservation strategies and policies, and produce results that can be translated into trends for indicators used in conservation. In contrast to the majority of LCIA models for biodiversity proposed until now, conservation frameworks aim to preserve ecologically functioning ecosystems of which many depend on continued sustainable human use of their biodiversity. LCIA models therefore need to assess impacts against references that include both natural and anthropogenic ecosystem states and processes in a manner that can account for long-term human occupancy and not only supposedly pristine landscapes. Several target reference situations and several indicators for the conservation status of biodiversity are used in conservation, many of which should be able to apply in LCIA models.

We call for the LCIA research community to collaborate with conservationists and ecologists in order to enable harmonization of biodiversity reference situations with current conservation strategies to improve the relevance of impact assessment models addressing biodiversity. That means that the reference situation should always reflect a desired situation and impact results will thus quantify the distance to a target rather than impact on the natural.
Acknowledgments The authors gratefully acknowledge Anne-Marie Tillman, Alexandre Antonelli, Christel Cederberg, Sofia Berg and Annie Jonsson for inspiring discussions and their contribution to an earlier conference paper that culminated in this paper.

Funding information The Swedish Research Council for Environment, Agricultural Sciences and Spatial Planning (FORMAS) gave support through funding the project "Bio-LCA" (grant no. 2014-00852).

\section{Compliance with ethical standards}

Conflict of interest The authors declare that they have no conflict of interest.

Open Access This article is distributed under the terms of the Creative Commons Attribution 4.0 International License (http:// creativecommons.org/licenses/by/4.0/), which permits unrestricted use, distribution, and reproduction in any medium, provided you give appropriate credit to the original author(s) and the source, provide a link to the Creative Commons license, and indicate if changes were made.

Publisher's note Springer Nature remains neutral with regard to jurisdictional claims in published maps and institutional affiliations.

\section{References}

Angelstam P, Andersson L (2001) Estimates of the needs for forest reserves in Sweden. Scand J For Res 3:38-51

Baumann H, Tillman A-M (2004) The hitch hiker's guide to LCA. An orientation in life cycle assessment methodology and application. Studentlitteratur AB, pp. 543

Blonk H, Lindeijer E, Broers J (1997) Towards a methodology for taking physical degradation of ecosystems into account in LCA. Int J Life Cycle Assess 2:91-98

Borja Á, Dauer DM, Grémare A (2012) The importance of setting targets and reference conditions in assessing marine ecosystem quality. Ecol Indic 12:1-7

Brander M (2016) Conceptualising attributional LCA is necessary for resolving methodological issues such as the appropriate form of land use baseline. Int J Life Cycle Assess 21:1816-1821

Brentrup F, Küsters J, Lammel J, Kuhlmann H (2002) Life cycle impact assessment of land use based on the hemeroby concept. Int J Life Cycle Assess 7:339-348

Cao V, Margni M, Favis BD, Deschênes L (2017) Choice of land reference situation in life cycle impact assessment. Int $\mathrm{J}$ Life Cycle Assess 22:1220-1231

Chaudhary A, Verones F, De Baan L, Hellweg S (2015) Quantifying land use impacts on biodiversity: combining species-area models and vulnerability indicators. Environ Sci Technol 49:9987-9995

Chiarucci A, Araújo MB, Decocq G, Beierkuhnlein C, FernándezPalacios JM (2010) The concept of potential natural vegetation: an epitaph? J Veg Sci 21:1172-1178

Churchman CW (1967) Wicked problems. Manag Sci 14:B-141-B-142

Curran M, De Baan L, De Schryver AM et al (2011) Toward meaningful endpoints of biodiversity in life cycle assessment. Environ Sci Technol 45:70-79

Curran M, Maia de Souza D, Antón A, Teixeira RFM, Michelsen O, Vidal-Legaz B, Sala S, Milà i Canals L (2016) How well does LCA model land use impacts on biodiversity? - a comparison with approaches from ecology and conservation. Environ Sci Technol 50: 2782-2795 
De Baan L, Alkemade R, Koellner T et al (2013a) Land use impacts on biodiversity in LCA: a global approach. Int J Life Cycle Assess 18: 1216-1230

de Baan L, Mutel CL, Curran M, Hellweg S, Koellner T (2013b) Land use in life cycle assessment: global characterization factors based on regional and global potential species extinction. Environ Sci Technol 47:9281-9290

De Baan L, Curran M, Rondinini C et al (2015) High-resolution assessment of land use impacts on biodiversity in life cycle assessment using species habitat suitability models. Environ Sci Technol 49: 2237-2244. https://doi.org/10.1021/es504380t

De Schryver AM, Goedkoop MJ, Leuven RSEW, Huijbregts MAJ (2010) Uncertainties in the application of the species area relationship for characterisation factors of land occupation in life cycle assessment. Int J Life Cycle Assess 15:682-691

Di Gregorio, A., and Jansen LJM (2000) Land cover classification system (LCCS): classification concepts and user manual. Fao. https://doi. org/10.1017/CBO9781107415324.004

Ekvall T, Tillman AM (1997) Open-loop recycling: criteria for allocation procedures. Int J Life Cycle Assess 2:155-162

Emanuelsson U (2010) The rural landscapes of Europe. How man has shaped European nature. Soc ekol Zagreb

Epstein Y, López-Bao JV, Chapron G (2016) A legal-ecological understanding of favorable conservation status for species in Europe. Conserv Lett 9:81-88

European Commission (2013) Interpretation Manual of European Union Habitats - EUR 28. Available at: http://ec.europa.eu/environment/ nature/legislation/habitatsdirective/docs/Int_Manual_EU28.pdf. Accessed 10 June 2018

Evans D (2010) Interpreting the habitats of annex I: past, present and future. Acta Bot Gall 157:677-686

Evans D, Arvela M (2011) Assessment and reporting under article 17 of the habitats directive explanatory notes $\&$ guidelines for the period 2007-2012.

FAO (2009) International treaty on plant genetic resources for food and agriculture. Rome

FAO (2002) Expert meeting on harmonizing forest-related definitions for use by various stakeholders. Rome

Frischknecht R, Fantke P, Tschümperlin L, Niero M, Antón A, Bare J, Boulay AM, Cherubini F, Hauschild MZ, Henderson A, Levasseur A, McKone TE, Michelsen O, i Canals LM, Pfister S, Ridoutt B, Rosenbaum RK, Verones F, Vigon B, Jolliet O (2016a) Global guidance on environmental life cycle impact assessment indicators: progress and case study. Int J Life Cycle Assess 21:429-442

Frischknecht R, Jolliet O, Milà i Canals L et al (2016b) Global guidance for life cycle impact assessment indicators. Volume 1

Gardner T (2010) Monitoring Forest biodiversity improving conservation through ecologically-responsible. Sustain Dev 67:388

Gerber LR, Hatch LT (2002) Are we recovering? An evaluation of recovery criteria under the U.S. endangered species act. Ecol Appl 12: 668-673

Groombridge B, Jenkins MD (2002) World atlas of biodiversity. University of California Press, Berkeley

Gusset M, Maddock AH, Gunther GJ, Szykman M, Slotow R, Walters M, Somers MJ (2008) Conflicting human interests over the reintroduction of endangered wild dogs in South Africa. Biodivers Conserv 17:83-101

Hamilton P (2002) The greening of nationalism: Nationalising nature in Europe. Env Polit 11:27-48

Hannah L, Lohse D, Hutchinson C et al (1994) A Prelininary inventory of human disturbance of world ecosystems. Biol Conserv 23:246-250

Hauschild MZ, Rosenbaum RK, Irving Olsen S (2017) Life cycle assessment: theory and practice. Springer, Berlin Heidelberg

Hilding Rydevik T, Moen J, Green C (2018) Baselines and the shifting baseline syndrome-exploring frames of reference in nature conservation. In: Crumley CL, Lennartsson T, Westin A (eds) Issues and concepts in historical ecology. Cambridge University Press

Huijbregts M (1999) Life-cycle impact assessment of acidifying and eutrophying air pollutants. IIASA, Laxenburg, p 32

Ices (2002) Report of the ICES advisory Committee in Ecosystems, 2002. Coop Res Rep 254:129

Ihse M (2007) Changes in the Scandinavian cultural landscape of imprtance for biodiversity. In: Hideborn Alm K (ed) Valuable agricultural landscapes - the importance of Romania and Scandinavia for Europe, 1200th edn. Barklund, Åke, pp 36-44

ISO (2006) ISO 14044: environmental management-life cycle assessment - requirements and guidelines. Environ Manag 3:54

IUCN (2016) Rules of procedure IUCN red list assessments 2017-2020

IUCN (2012) Guidelines for application of IUCN red list criteria at regional and National Levels: version 4.0. Gland, Switzerland and Cambridge, UK

Iuga A, Westin A, Lancu B et al (2018) Rural communities and traditional ecological knowledge. In: Crumley CL, Lennartsson T, Westin A (eds) Issues and concepts in historical ecology. Cambridge University Press

Jeanneret P, Baumgartner DU, Freiermuth Knuchel R, Koch B, Gaillard G (2014) An expert system for integrating biodiversity into agricultural life-cycle assessment. Ecol Indic 46:224-231

Jennings S, Dulvy NK (2005) Reference points and reference directions for size-based indicators of community structure. ICES J Mar Sci 62:397-404

Joseph LN, Maloney RF, Possingham HP (2009) Optimal allocation of resources among threatened species: a project prioritization protocol. Conserv Biol 23:328-338

Kapos V, Lysenko I (2000) Assessing forest naturalness and integrity in relation to biodiversity. FRA 2000 on behalf of FAO as part of the global Forest resources Assessment 2000

Keddy PA (2010) Wetland ecology: principles and conservation. Cambridge University Press

Koellner T, de Baan L, Beck T, Brandão M, Civit B, Margni M, i Canals LM, Saad R, de Souza DM, Müller-Wenk R (2013) UNEP-SETAC guideline on global land use impact assessment on biodiversity and ecosystem services in LCA. Int J Life Cycle Assess 18:1188-1202

Koellner T, Geyer R (2013) Global land use impact assessment on biodiversity and ecosystem services in LCA. Int J Life Cycle Assess 18: $1185-1187$

Koellner T, Scholz RW (2008) Assessment of land use impacts on the natural environment. Part 2: generic characterization factors for local species diversity in Central Europe. Int J Life Cycle Assess 13:3248. https://doi.org/10.1065/lca2006.12.292.2

Kopf RK, Finlayson CM, Humphries P, Sims NC, Hladyz S (2015) Anthropocene baselines: assessing change and managing biodiversity in human-dominated aquatic ecosystems. Bioscience 65:798-811

Koponen K, Soimakallio S, Kline KL, Cowie A, Brandão M (2018) Quantifying the climate effects of bioenergy - choice of reference system. Renew Sust Energ Rev 81:2271-2280

Lennartsson T, Eriksson O, Iuga A et al (2018) Diversity in ecological and social context. In: Crumley CL, Lennartsson T, Westin A (eds) Issues and concepts in historical ecology. Cambridge University Press

Lennartsson T, Helldin J-O (2007) Agricultural landscapes in Eastern Europe as reference areas for Swedish land management. In: Hideborn Alm K (ed) Valuable agricultural landscapes - the importance of Romania and Scandinavia for Europe. Barklund, Åke

Lindeijer E (2000) Biodiversity and life support impacts of land use in LCA. J Clean Prod 8:313-319

Lindeijer E, Kok I, Eggels P, Alfers A (2002) Improving and testing a land use methodology for LCA, including case-studies on bricks, concrete and wood. pp. 1-131 
Lindner JP, Niblick B, Eberle U et al (2014) Proposal of a unified biodiversity impact assessment method. In: 9th international conference LCA of food. San Francisco, pp 6-11

Lindqvist M, Palme U, Lindner JP (2015) A comparison of two different biodiversity assessment methods in LCA - a case study of Swedish spruce forest. Int J Life Cycle Assess 21:190-201

Margules CR, Pressey RL (2000) Systematic conservation planning. Nature 405:243-253

Marsh H, Dennis A, Hines H et al (2007) Optimizing allocation of management resources for wildlife. Conserv Biol 21:387-399

Medaglia J, Phillips F, Perron-Welch F et al (2014) Biodiversity legislation study - a review of biodiversity legislation in 8 countries

Michelsen O (2008) Assessment of land use impact on biodiversity. Int J Life Cycle Assess 13:22-31

Michelsen O, Lindner J (2015) Why include impacts on biodiversity from land use in LCIA and how to select useful indicators? Sustainability 7:6278-6302

Michelsen O, McDevitt JE, Coelho CRV (2014) A comparison of three methods to assess land use impacts on biodiversity in a case study of forestry plantations in New Zealand. Int J Life Cycle Assess 19: 1214-1225

Mihoub J-B, Henle K, Titeux N, Brotons L, Brummitt NA, Schmeller DS (2017) Setting temporal baselines for biodiversity: the limits of available monitoring data for capturing the full impact of anthropogenic pressures. Sci Rep 7:41591

Milà i Canals L, Clift R, Basson L, Hansen Y, Brandão M (2006) Expert Workshop on Land Use Impacts in Life Cycle Assessment. 12-13 June 2006 Guildford, Surrey (UK). Int J Life Cycle Assess 11:363-368

Milà i Canals L, Bauer C, Depestele J, Dubreuil A, Freiermuth Knuchel R, Gaillard G, Michelsen O, Müller-Wenk R, Rydgren B (2007) Key elements in a framework for land use impact assessment within LCA. Int J Life Cycle Assess 12:5-15

Miller SJ, Pruitt BA, Theiling CH et al (2012) Reference concepts in ecosystem restoration and environmental benefits analysis (EBA): principles and practices

Nielsen SE, Bayne EM, Schieck J, Herbers J, Boutin S (2007) A new method to estimate species and biodiversity intactness using empirically derived reference conditions. Biol Conserv 137:403-414

Nogués-Bravo D, Simberloff D, Rahbek C, Sanders NJ (2016) Rewilding is the new pandora's box in conservation. Curr Biol 26:87-91

Nordborg M, Sasu-Boakye Y, Cederberg C, Berndes G (2017) Challenges in developing regionalized characterization factors in land use impact assessment: impacts on ecosystem services in case studies of animal protein production in Sweden. Int J Life Cycle Assess 22:328-345

Norderhaug A (2007) Biological and cultural landscape values - why and how to maintain them? In: Hideborn Alm K, Hasund KP, Helldin J$\mathrm{O}$ (eds) Valuable agricultural landscapes - the importance of Romania and Scandinavia for Europe. Åke Barklund, Secretary General and Managing Director, KSLA, pp 31-35

Opperman R, Paracchini ML (2012) HNV farming - central to European cultural landscapes and biodiversity. In: Oppermann R, Beaufoy G, Jones $\mathrm{G}$ (eds) High nature value farming in Europe. verlag regionalkultur, Ubstadt-Weiher, pp 16-23

Pereira HM, Navarro LM (2015) Rewilding European landscapes. Springer International Publishing, Berlin Heidelberg

Pitcher TJ (2001) Fisheries managed to rebuild ecosystems? Reconstructing the past to salvage the future. Ecol Appl 11:601-617

Pressey RL, Cowling RM, Rouget M (2003) Formulating conservation targets for biodiversity pattern and process in the cape floristic region, South Africa. Biol Conserv 112:99-127

Putman RJ, Wratten SD (1984) Principles of ecology. Chapman and Hall Ltd, london

Ramsar Convention Secretariat (2013) The Ramsar Convention manual
Reif A, Walentowski H (2008) The assessment of naturalness and its role for nature conservation and forestry in Europe. Waldökologie, Landschaftsforsch und Naturschutz 6:63-76

Rice J (2003) Environmental health indicators. In: Ocean and Coastal Management. pp 235-259

Ricotta C, Carranza ML, Avena G, Blasi C (2002) Are potential natural vegetation maps a meaningful alternative to neutral landscape models? Appl Veg Sci 5:271-275

Schindler DW (1974) Eutrophication and recovery in experimental lakes: implications for lake management. Science (80-) 184:897-899

Scholes RJ, Biggs R (2005) A biodiversity intactness index. Nature 434: 45-49

Sharman M, Mlambo MC (2012) Wicked: the problem of biodiversity loss. Gaia 21:274-277

Soimakallio S, Cowie A, Brandão M, Finnveden G, Ekvall T, Erlandsson M, Koponen K, Karlsson PE (2015) Attributional life cycle assessment: is a land-use baseline necessary? Int J Life Cycle Assess 20: $1364-1375$

Soulé M, Noss R (1998) Rewilding and biodiversity: complementary goals for continental conservation. Wild Earth 8:18-28

Souza DM, Flynn DFB, Declerck F et al (2013) Land use impacts on biodiversity in LCA: proposal of characterization factors based on functional diversity. Int J Life Cycle Assess 18:1231-1242

Souza DM, Teixeira RFM, Ostermann OP (2015) Assessing biodiversity loss due to land use with life cycle assessment: are we there yet? Glob Chang Biol 21:2132-2147

Stoddard JL, Larsen DP, Hawkins CP, Johnson RK, Norris RH (2006) Setting expectations for the ecological condition of streams: the concept of reference condition. Ecol Appl 16:1267-1276

Swedish Species Information Centre (2015) "The red list of Sweden 2015." Artdatabanken, SLU; Uppsala

Teillard F, Maia de Souza D, Thoma G, Gerber PJ, Finn JA, Bode M (2016) What does Life-Cycle Assessment of agricultural products need for more meaningful inclusion of biodiversity? J Appl Ecol 53(5): 1422-1429

Teixeira RFM, Maia de Souza D, Curran MP, Antón A, Michelsen O, Milà i Canals L (2016) Towards consensus on land use impacts on biodiversity in LCA: UNEP/SETAC life cycle initiative preliminary recommendations based on expert contributions. J Clean Prod 112:4283-4287

The Council of the European Communities (2013) Council Directive 92/ 43/EEC of 21 May 1992 on the conservation of natural habitats and of wild fauna and flora. Off J Eur Communities L 269:1-15

UN CBD (2010) United Nations convention on biological diversity conference of the parties 10 decision X/2. Strateg Plan Biodivers 2011-2020:1-13

Tüxen R (1956) Die heutige potentielle natürliche Vegetation als Gegenstand der Vegetationskartierung. Angewandte Pflanzensoziologie 13:5-55

UNEP (2016) Enhancing synergies across global biodiversity conventions - experiences from the global south workshop proceedings and country reports. Nairobi

Verones F, Bare J, Bulle C, Frischknecht R, Hauschild M, Hellweg S, Henderson A, Jolliet O, Laurent A, Liao X, Lindner JP, Maia de Souza D, Michelsen O, Patouillard L, Pfister S, Posthuma L, Prado V, Ridoutt B, Rosenbaum RK, Sala S, Ugaya C, Vieira M, Fantke P (2017) LCIA framework and cross-cutting issues guidance within the UNEP-SETAC life cycle initiative. J Clean Prod 161:957-967

Vidal Legaz B, Maia De Souza D, Teixeira RFM et al (2017) Soil quality, properties, and functions in life cycle assessment: an evaluation of models. J Clean Prod 140:502-515

Vrasdonk E, Palme U, Lennartsson T et al (2016) Defining the reference situation for biodiversity in life cycle assessments: review and recommendations. In: 1Proceedings of the 10th international conference on life cycle assessment of food 2016. Dublin, pp 620-628

Wagendorp T, Gulinck H, Coppin P, Muys B (2006) Land use impact evaluation in life cycle assessment based on ecosystem thermodynamics. Energy 31:112-125 
Walters CJ, Martell SJD (2004) Fisheries ecology and management. Fish Manag Ecol 6:399

Weidema BP, Lindeijer E (2001) Physical impacts of land use in product life cycle assessment. Final report of the EURENVIRONLCAGAPS sub-project on land use, Lungby

Willis KJ, Gillson L, Brncic TM (2004) How "virgin" is virgin rainforest? Science (80-) 304:402-403

Willis KJ, Gillson L, Knapp S (2007) Biodiversity hotspots through time: an introduction. Philos Trans R Soc B Biol Sci 362:169-174
Winter L, Lehmann A, Finogenova N, Finkbeiner M (2017) Including biodiversity in life cycle assessment - state of the art, gaps and research needs. Environ Impact Assess Rev 67:88-100

Winter L, Pflugmacher S, Berger M, Finkbeiner M (2018) Biodiversity impact assessment (BIA+) - methodological framework for screening biodiversity. Integr. Environ Assess Manag 14(2):282-297 